\title{
The aetiology and antibiotic management of community-acquired pneumonia in adults in Europe: a literature review
}

\author{
A. Torres • F. Blasi • W. E. Peetermans • G. Viegi • \\ T. Welte
}

Received: 10 December 2013 / Accepted: 15 January 2014 / Published online: 15 February 2014

(C) The Author(s) 2014. This article is published with open access at Springerlink.com

\begin{abstract}
The purpose of this paper was to generate up-to-date information on the aetiology of community-acquired pneumonia (CAP) and its antibiotic management in adults across Europe. Structured searches of PubMed identified information on the aetiology of CAP and its antibiotic management in individuals aged $>15$ years across Europe. We summarise the data from 33 studies published between January 2005 and July 2012 that reported on the pathogens identified in patients with CAP and antibiotic treatment in patients with CAP. Streptococcus pneumoniae was the most commonly isolated pathogen in patients with CAP and was identified in $12.0-85.0 \%$ of patients. Other frequently identified pathogens found to cause CAP were Haemophilus influenzae, Gram-negative enteric
\end{abstract}

Electronic supplementary material The online version of this article (doi:10.1007/s10096-014-2067-1) contains supplementary material, which is available to authorized users.

\section{A. Torres $(\square)$}

Servei de Pneumologia, Hospital Clínic de Barcelona, Institut

d'Investigacions Biomèdiques August Pi i Sunyer (IDIBAPS), CIBER de Enfermedades Respiratorias (CIBERes), University of

Barcelona, Barcelona, Spain

e-mail: ATORRES@clinic.ub.es

\section{F. Blasi}

Department of Pathophysiology and Transplantation, University of Milan, IRCCS Fondazione Ca' Granda Ospedale Maggiore, Milan, Italy

W. E. Peetermans

Department of Internal Medicine, University Hospital, KU Leuven, Leuven, Belgium

G. Viegi

CNR Institute of Clinical Physiology, Pisa, and CNR Institute of Biomedicine and Molecular Immunology, Palermo, Italy

T. Welte

Department of Respiratory Medicine, Medizinische Hochschule, Hannover, Germany bacilli, respiratory viruses and Mycoplasma pneumoniae. We found several age-related trends: S. pneumoniae, $H$. influenzae and respiratory viruses were more frequent in elderly patients aged $\geq 65$ years, whereas $M$. pneumoniae was more frequent in those aged $<65$ years. Antibiotic monotherapy was more frequent than combination therapy, and beta-lactams were the most commonly prescribed antibiotics. Hospitalised patients were more likely than outpatients to receive combination antibiotic therapy. Limited data on antibiotic resistance were available in the studies. Penicillin resistance of S. pneumoniae was reported in $8.4-20.7 \%$ of isolates and erythromycin resistance was reported in $14.7-17.1 \%$ of isolates. Understanding the aetiology of CAP and the changing pattern of antibiotic resistance in Europe, together with an increased awareness of the risk factors for CAP, will help clinicians to identify those patients most at risk of developing CAP and provide guidance on the most appropriate treatment.

\section{Introduction}

The clinical and economic burden of community-acquired pneumonia (CAP) in Europe is substantial. A review of the burden of CAP in Europe demonstrated that the incidence of CAP and hospitalisations for CAP are rising [1]. The incidence of CAP was shown to be higher in men than in women and to increase with age. In addition to increasing age [1-3], several other risk factors for CAP have been established, including smoking [2], immunosuppression [3] and the presence of comorbid conditions [4-7]. With an ageing population in Europe, the clinical and economic burden of CAP is expected to continue to rise over time, placing increasing pressure on hospital resources and society [1,8-11].

Streptococcus pneumoniae is widely accepted as being the most common pathogen causing CAP. However, the frequency at which it is identified varies considerably between studies across Europe $[1,12]$. In addition to $S$. pneumoniae, several 
other pathogens cause CAP, including atypical pathogens such as Legionella pneumophila and Staphylococcus aureus, and Gram-negative bacilli, including Pseudomonas aeruginosa [13-18].

It is important to understand the emerging role of different pathogens in the aetiology of CAP to effectively guide appropriate antibiotic management [19]. Inappropriate antibiotic treatment in patients with CAP has been repeatedly linked with worse outcomes [20-23]. This literature review was conducted to generate up-to-date information on the aetiology of CAP and its antibiotic management in adults across Europe.

\section{Methods}

The search methodology for this literature review was the same as that described for a previous literature search and analysis [7], but with additional filters for the topics of interest to this review (Fig. 1).

The PubMed database was searched using the following search string: pneumonia AND English AND 2005/01/012012/07/31 AND risk NOT clinical trial, phase I OR clinical trial, phase II OR clinical trial, phase III OR controlled clinical trial OR randomized controlled trial OR case reports OR practice guideline OR editorial OR review OR cost OR cost effectiveness OR efficacy OR immunogenicity OR economic OR nosocomial. Additional searches used the same search string, but replaced 'risk' with either 'comorbidity' or 'comorbidity'.

Articles were included in the initial literature search [7] if they reported observational studies performed in Western European countries (Austria, Belgium, Denmark, Finland, France, Germany, Greece, Ireland, Italy, The Netherlands, Norway, Portugal, Spain, Sweden, Switzerland, UK) and
Fig. 1 Summary of the study selection procedure. (Adapted from Fig. 1 of Torres et al. [7], used under the Creative

Commons-Attribution-

NonCommercial (CC BY-NC

3.0) license. The original can be found here: http://thorax.bmj. com/content/68/11/1057/F1. large.jpg). $C A P$ communityacquired pneumonia. * One study did not include the terms 'risk' or 'co-morbidity'/"comorbidity' in either the title or the abstract and, so, was not identified in the PubMed searches; however, 'risk factors' was included in the list of $\mathrm{MeSH}$ terms for the article

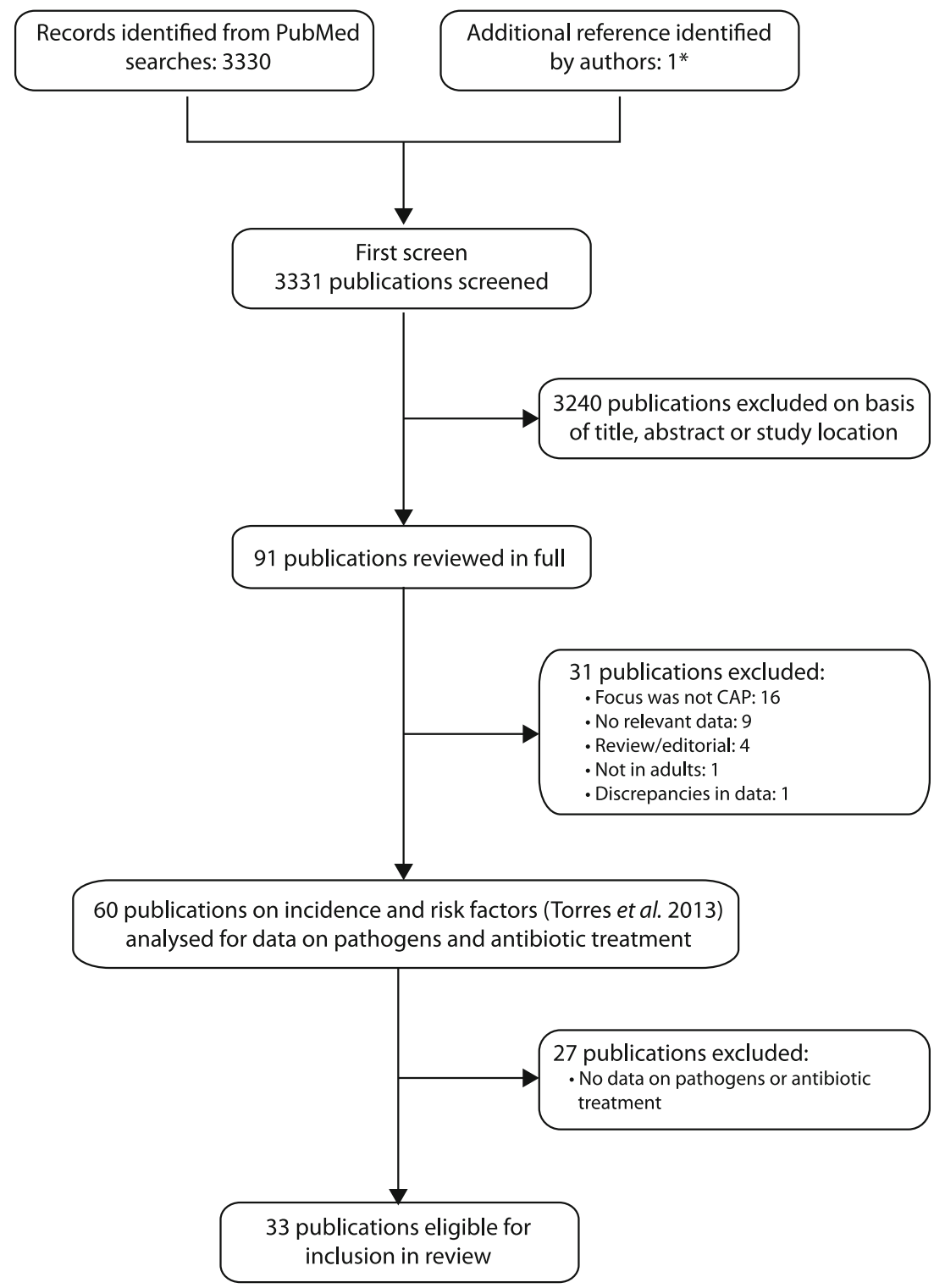


presented data from individuals $>15$ years of age on either the incidence of CAP in at-risk individuals, defined as those with underlying risk factors placing them at increased risk of CAP (as defined in [7]), or risk factors for CAP. The papers identified were further screened for data on pathogens identified in patients with CAP and/or antibiotic treatment in patients with CAP. Studies that focused on nosocomial or healthcareacquired pneumonia were excluded.

The included articles were reviewed in full and data on the study setting and methodology, characteristics of the populations studied, pathogens and antibiotic treatments were extracted. If more than one paper reported different aspects of the same study, all relevant papers were included. Where the same data were reported in more than one paper, the first paper to be published was selected for inclusion. The analysis of the included papers was descriptive and no meta-analyses of data were performed. Unless otherwise stated, all data are reported as odds ratios (ORs) (95\% confidence intervals [CIs]).

\section{Results}

\section{Included studies}

As reported previously [7], a total of 3,331 articles published between January 2005 and July 2012 were identified, of which 3,240 could be excluded on the basis of the title, abstract or study location. Further screening of the PubMed results and full papers identified 60 references meeting the inclusion and exclusion criteria. We summarise data from 33 of these studies that reported on the pathogens identified in patients with CAP and/or antibiotic treatment in patients with CAP. The included studies were performed in Denmark $(n=1)$, France $(n=3)$, Germany $(n=3)$, Greece $(n=1)$, Italy $(n=4)$, Spain $(n=20)$ and the UK $(n=1)$. Details of the study designs and populations are summarised in Table 1.

The majority of studies included adults of all ages, but three studies considered only elderly patients (age $\geq 65$ years) [24-26]. Additionally, most of the studies considered pneumonia of any aetiology, but six were performed in patients with pneumonia due to L. pneumophila $(n=3)$ [27-29], Haemophilus influenzae $(n=1)$ [30], Gram-negative bacteria $(n=1)$ [31], or Enterobacteriaceae or P. aeruginosa $(n=1)$ [32]. Six studies were conducted in specific populations: five studies in patients with human immunodeficiency virus (HIV) [33-37] and one study in patients with chronic obstructive pulmonary disease (COPD) [38].

Pathogens identified in patients with CAP

The aetiology of CAP was investigated in 25 observational studies in Denmark $(n=1)$, France $(n=2)$, Germany $(n=2)$, Italy $(n=2)$, Spain $(n=17)$ and the UK $(n=1)$. Tables 2,3 and 4 summarise these data to show the most common microbiological techniques, the overall frequency of isolation of pathogens and the frequency of isolation of pathogens specifically in HIV and COPD study cohorts. Full details of the microbiological techniques used and the pathogens isolated in each study are included in Supplementary Table 1.

Microbiological methodologies used to establish the aetiology of CAP were reported in $67 \%$ of the studies $(n=22)$. These methodologies were similar across studies and included the assessment of blood, sputum, urine and pleural fluid samples and, less commonly, tracheobronchial, bronchoalveolar, transthoracic and nasopharyngeal samples. Blood cultures were performed in all 22 studies (Table 2) and all but one study reported using at least two different techniques. Other frequently used techniques for the isolation of pathogens were sputum culture (91\% of studies), urine antigen tests (specifically for the detection of $S$. pneumoniae and L. pneumophila; $86 \%$ of studies), serology, for the detection of antibodies against specific pathogens, including L. pneumophila, Chlamydophila pneumoniae, Coxiella burnetii, Mycoplasma pneumoniae, Chlamydophila psittaci, Chlamydia trachomatis and respiratory viruses (68 \% of studies), and pleural fluid culture ( $45 \%$ of studies).

The percentages of patients and episodes of CAP in which a pathogen was not identified were $26.7-87.3 \%$ and 44.2 $77.0 \%$, respectively. In patients in whom a pathogen was identified, $S$. pneumoniae was the most commonly isolated and was identified in $12.0-85.0 \%$ of patients within 19 studies (Table 3). Of the atypical bacteria, M. pneumoniae (up to $61.3 \%$ of patients within ten studies), L. pneumophila (up to $20.1 \%$ of patients within 12 studies) and C. pneumoniae (up to $9.9 \%$ of patients within nine studies) were frequently identified in patients with CAP, whereas C. burnetii was isolated less frequently (up to $3.4 \%$ of patients within six studies). Other pathogens isolated included $S$. aureus (up to $20.0 \%$ of patients within 12 studies), P. aeruginosa (up to $16.8 \%$ of patients within ten studies), Klebsiella pneumoniae (up to $5.0 \%$ of patients within five studies) and Acinetobacter baumannii (isolated in $2.0 \%$ of patients in one study that was performed in patients hospitalised with bacteraemic CAP due to Gram-negative bacteria [31]). CAP of mixed aetiology was reported in four studies in $0.4-19.9 \%$ of patients [22, 26, 39, 40].

For studies with data available stratified by age $(<65$ years and/or $\geq 65$ years) [23-26, 40, 41], the frequencies of pathogens were generally similar between age groups. However, S. pneumoniae ( $<65$ years: $20.9-28.0 \%$; $\geq 65$ years: 19.9 $85.0 \%$ ), H. influenzae ( $<65$ years: $4.1-6.4 \%$; $\geq 65$ years: 2.9 $29.4 \%)$ and respiratory viruses $(<65$ years: $4.6-7.7 \%$; $\geq 65$ years: $7.8-18.6 \%$ ) appeared to be more frequently isolated in elderly patients aged $\geq 65$ years, and $M$. pneumoniae appeared to be more frequently isolated in younger patients ( $<65$ years: $14.0-25.1 \%$; $\geq 65$ years: $0.7-6.8 \%$ ). 

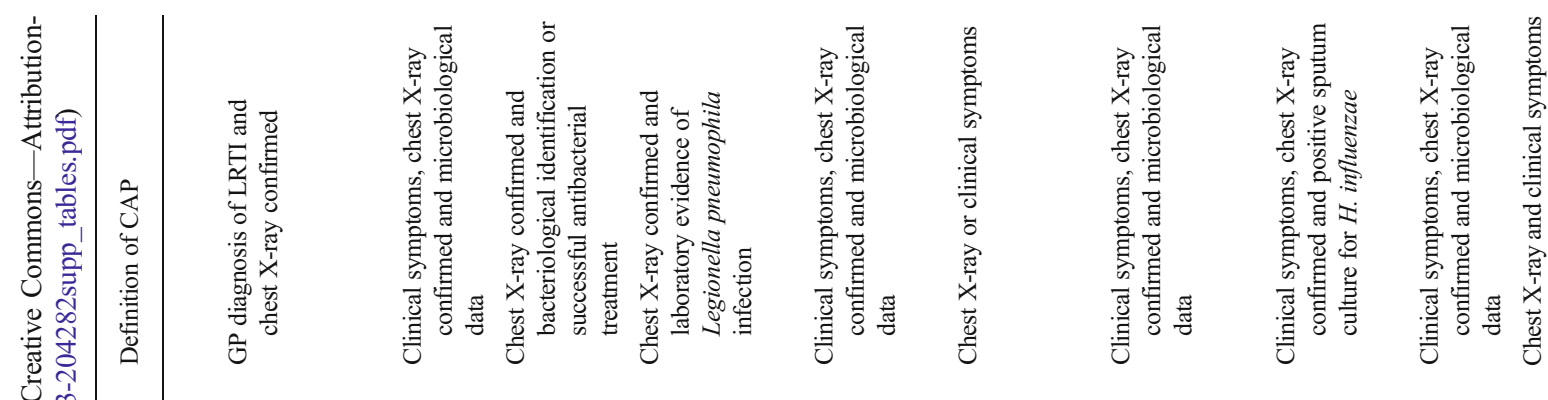

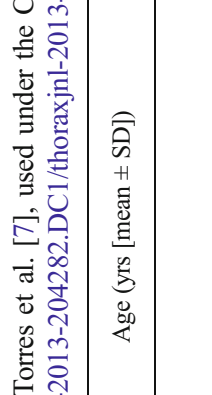
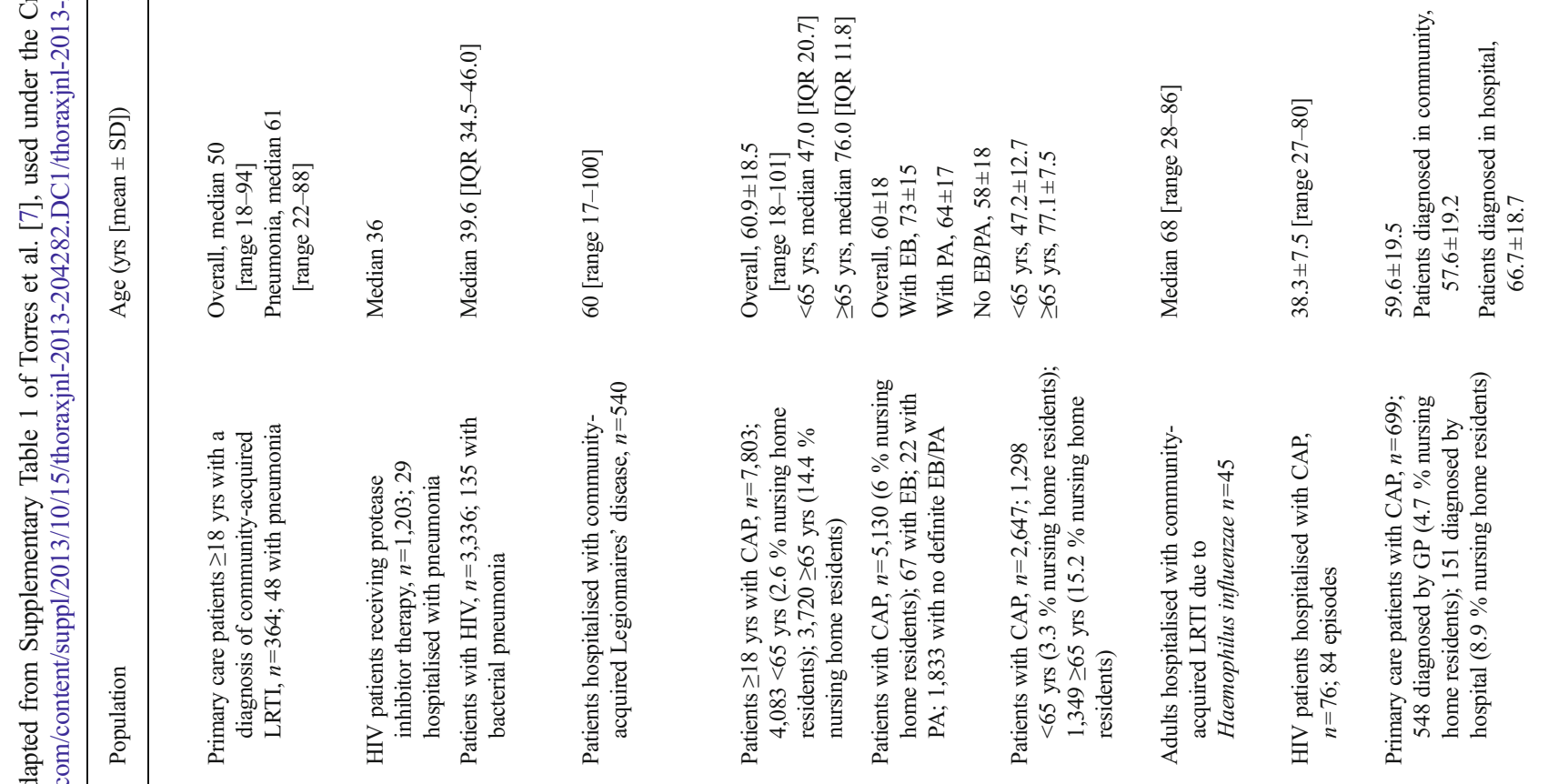

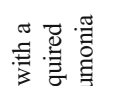
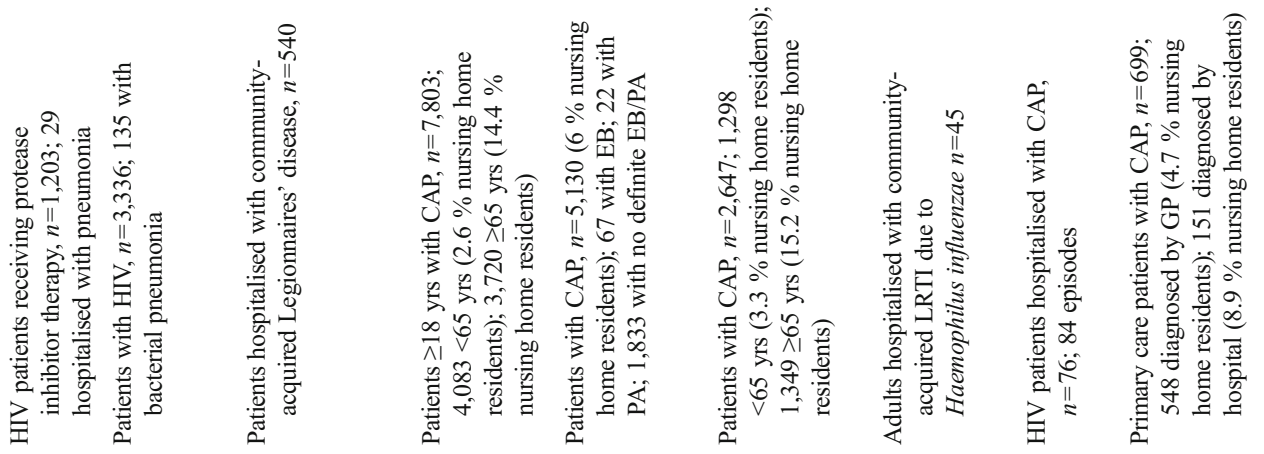

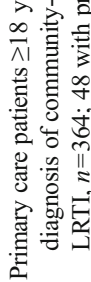

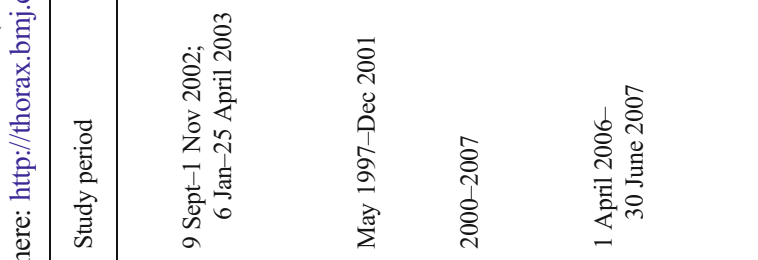

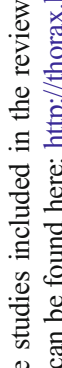

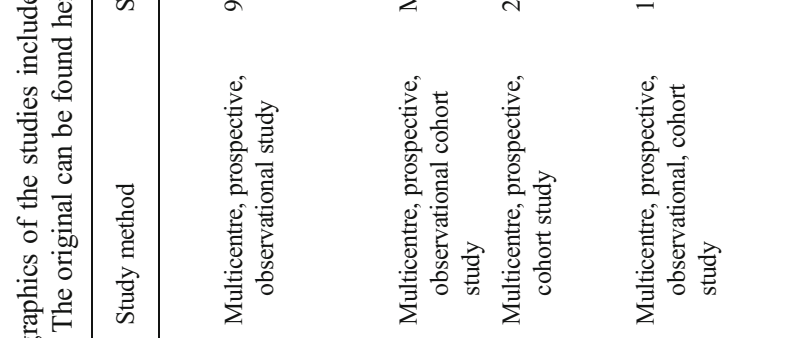

50

密

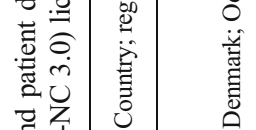

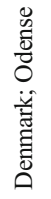

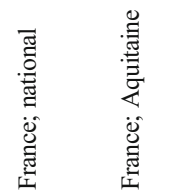

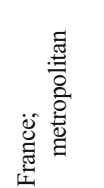

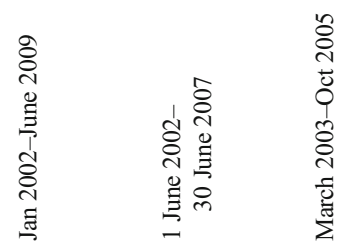

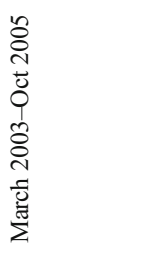

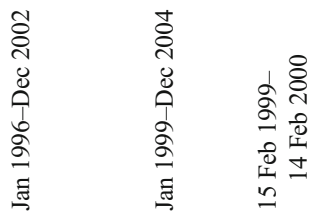

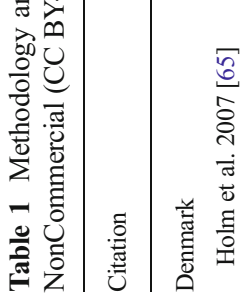

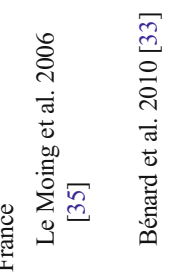

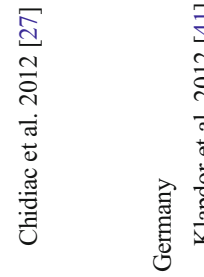

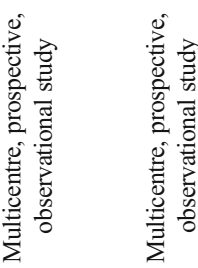

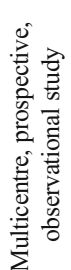
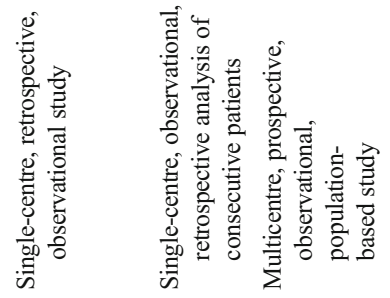

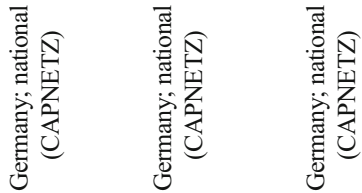

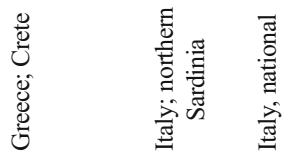




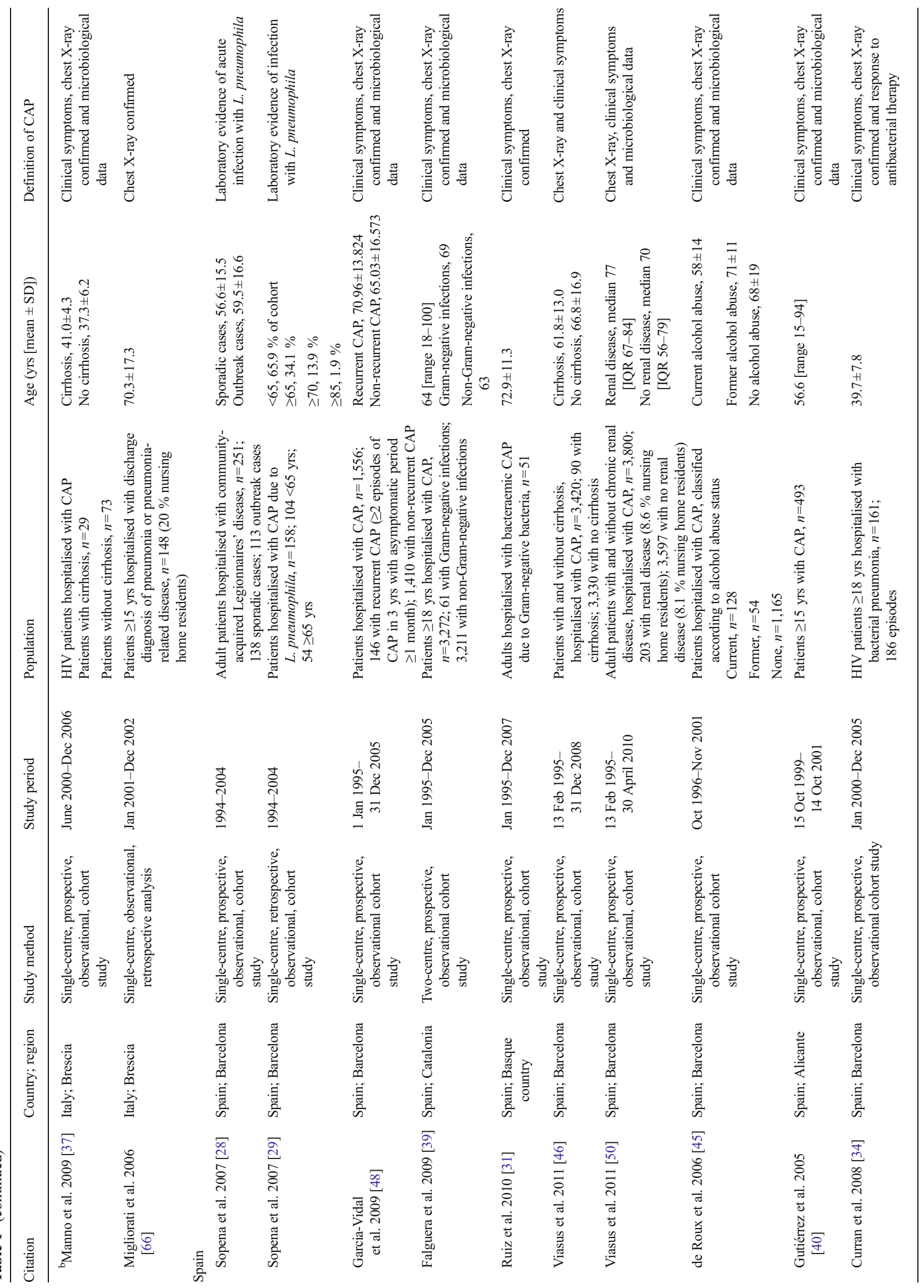




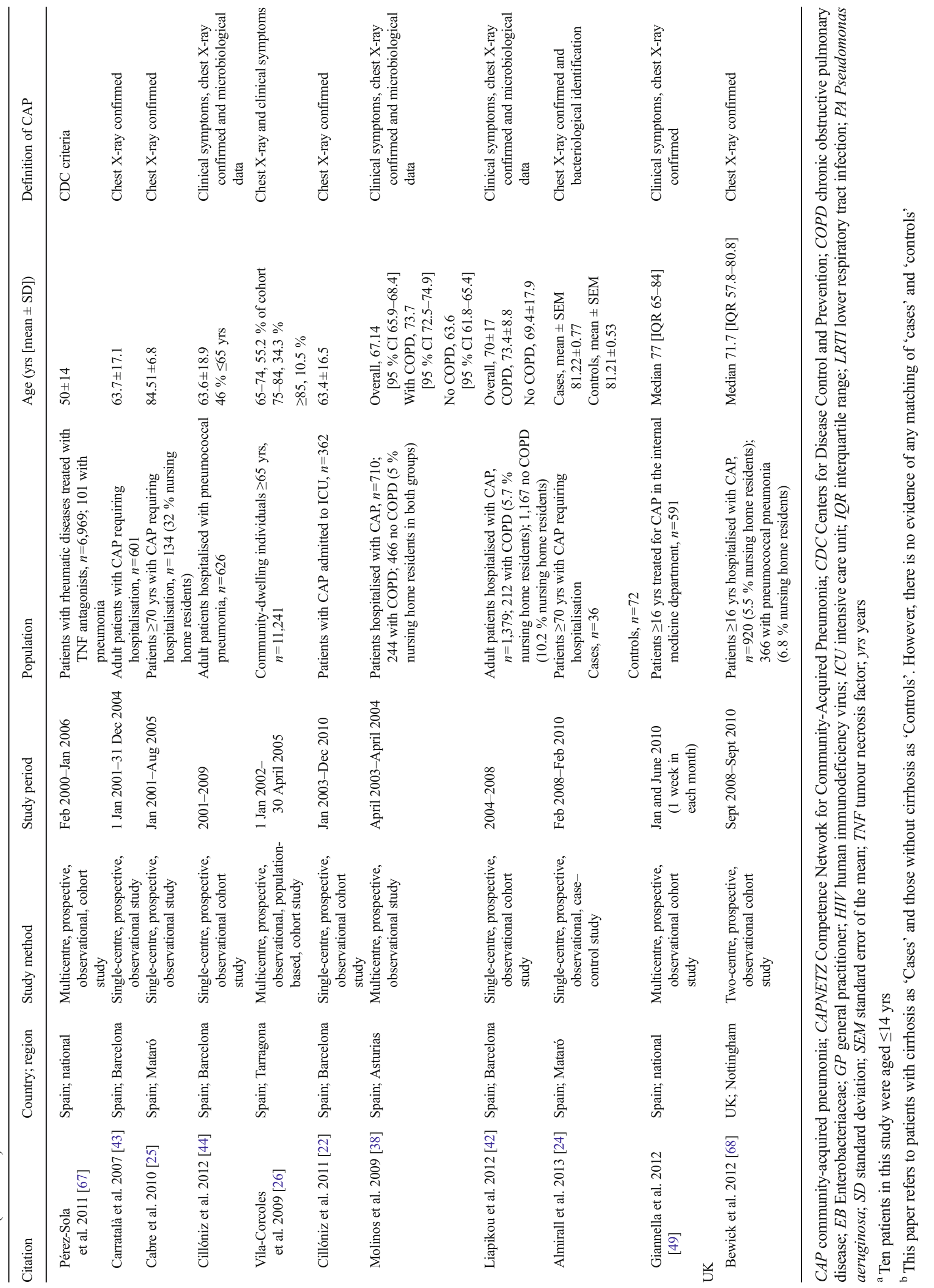


Table 2 Microbiological techniques/samples used for the isolation of pathogens in patients with CAP

\begin{tabular}{lll}
\hline Microbiological technique/sample & Number of studies using technique, $n(\%)$ & References \\
\hline Blood culture & $22(100)$ & {$[22-24,26,31,34-43,45,46,48-50,65,68]$} \\
Sputum culture & $20(91)$ & {$[22-24,26,34,36-43,45,46,48-50,65,68]$} \\
Urine antigen test $^{\mathrm{a}}$ & $19(86)$ & {$[22-24,26,31,34,36,38-43,45,46,48-50,68]$} \\
Blood serology $^{\mathrm{b}}$ & $15(68)$ & {$[22,26,36,38-43,45,46,48-50,68]$} \\
Pleural fluid & $10(45)$ & {$[22-24,34,38-40,42,45,50]$} \\
Tracheobronchial aspirate $_{\text {Bronchoalveolar lavage }}$ & $7(32)$ & {$[22-24,38,42,45,49]$} \\
Transthoracic needle aspirate & $6(27)$ & {$[22,23,37,45,49,68]$} \\
Normally sterile fluid culture & $4(18)$ & {$[23,39,45,49]$} \\
Nasopharyngeal swab & $3(14)$ & {$[43,46,48]$} \\
Sublingual smear & $3(14)$ & {$[22,41,49]$} \\
\hline
\end{tabular}

$C A P$ community-acquired pneumonia; $n$ number of studies using the given technique of the 22 studies reporting the microbiological techniques used for the isolation of pathogens in patients with CAP

${ }^{a}$ For the detection of Streptococcus pneumoniae and Legionella pneumophila

${ }^{\mathrm{b}}$ For the detection of antibodies against specific pathogens or groups of pathogens, including Legionella pneumophila, Chlamydophila pneumoniae, Coxiella burnetii, Mycoplasma pneumoniae, Chlamydophila psittaci, Chlamydia trachomatis and respiratory viruses

Among the studies reporting on the aetiology of CAP in patients with HIV [33-37], the frequencies of isolated pathogens were similar to those found for the overall data. $S$. pneumoniae was the most commonly isolated pathogen (57.8-81.8\% of patients), and H. influenzae and L. pneumophila were also often identified (Table 4).

The aetiology of CAP was similar in patients with and without COPD [38, 40, 42], in whom S. pneumoniae, $H$. influenzae, L. pneumophila, M. pneumoniae and respiratory viruses were all commonly identified (Table 4$)$. In one study, $P$. aeruginosa was reported in a significantly higher percentage of patients with COPD than in those without COPD $(7.4 \%$ vs. $0.9 \% ; p<0.01)$ and $L$. pneumophila was found to be significantly lower in patients with COPD than in those without COPD (2.1\% vs. $7.8 \% ; p<0.05)$ [42].

Antibiotic treatment in patients with CAP

The antibiotic treatment of patients with CAP was reported in 23 studies: France $(n=1)$, Germany $(n=3)$, Greece $(n=1)$, Italy $(n=4)$ and Spain $(n=14)$. Rates of antibiotic treatment with beta-lactams, macrolides and quinolones are summarised in Table 5. Full details of the antibiotic therapies for each study are provided in Supplementary Table 2.

The rates of antibiotic treatments in patients with CAP were available in 13 studies $[22,28,29,36-38,40,41$, 43-47]. The rate of monotherapy ranged from 16.0 to $94.7 \%$ of patients and the rate of combination antibiotic therapy ranged from 5.0 to $84.0 \%$ of patients (Table 5). The rate of antibiotic monotherapy with beta-lactams was higher than that for macrolides and quinolones. In one study, younger patients ( $<65$ years) received fewer beta-lactams and more quinolones than older patients ( $\geq 65$ years) (beta-lactams: $62.5 \%$ vs. $81.3 \%$; quinolones: $28.2 \%$ vs. $17.1 \%$, respectively), whereas macrolide use was similar between age groups ( $32.6 \%$ vs. $31.4 \%$, respectively) [41]. For combination therapy, the most common combinations were betalactams combined with macrolides or quinolones. We found that the rate of combination antibiotic therapy was higher in patients in an intensive care unit (ICU; $84.0 \%$ ) and other hospitalised patients (31.8-69.0\%) than in outpatients (5.0 $29.9 \%$ ) (Table 6). Three studies reported data on antibiotic treatment in populations with comorbidities (COPD [38] and liver disease [46]) or lifestyle risk factors for CAP (alcoholism [45]). Antibiotic treatments did not differ according to the presence or absence of COPD, liver disease or alcoholism.

In the 14 studies that reported on appropriate versus inappropriate antibiotic therapy $[22,23,27-31,43,44,46-50]$, the majority of patients had received adequate initial antibiotic treatment. Inappropriate antibiotic therapy was reported in 0 $39.0 \%$ of patients $[22,23,27-32,43,44,46,48-50]$. One study showed that patients with polymicrobial CAP were significantly more likely than those with monomicrobial CAP $(p<0.001)$ to receive inappropriate antibiotic treatment ( $39.0 \%$ vs. $10.0 \%$, respectively) [22]. Furthermore, inappropriate antibiotic therapy was found to be an independent predictor of mortality (univariate analysis: OR 11.23 [95\% CI 4.44-28.38], $p<0.001$; multivariate analysis: adjusted OR 10.79 [3.97-29.30], $p<0.001)$ in one study [22].

The antibiotic resistance of pathogens responsible for CAP was described in four studies conducted in 1995-2008 [46], 2001 [45], 2001-2004 [43], 2001-2009 [44] and 2002 [30]. Penicillin resistance of $S$. pneumoniae was reported in 14.9$25.7 \%$ of patients with CAP and in $8.4-20.7 \%$ of isolates. 
Table 3 Patients with CAP and episodes of CAP with a pathogen identified

\begin{tabular}{|c|c|c|c|c|c|c|c|}
\hline \multirow[t]{2}{*}{ Aetiology } & \multicolumn{3}{|c|}{ Patients with pathogen identified ${ }^{\mathrm{a}}$} & \multicolumn{3}{|c|}{ Episodes with pathogen identified $^{\mathrm{a}}$} & \multirow[t]{2}{*}{ References } \\
\hline & $\begin{array}{l}\text { Cohorts } \\
(n)^{\mathrm{b}}\end{array}$ & $\begin{array}{l}\text { Studies } \\
(n)\end{array}$ & Range (\%) & $\begin{array}{l}\text { Cohorts } \\
(n)^{\mathrm{b}}\end{array}$ & $\begin{array}{l}\text { Studies } \\
(n)\end{array}$ & Range (\%) & \\
\hline \multicolumn{8}{|l|}{ Gram-positive bacteria } \\
\hline $\begin{array}{l}\text { Streptococcus } \\
\text { pneumoniae }\end{array}$ & 51 & 19 & $12.0-85.0$ & 6 & 5 & $3.2-19.2$ & {$[22-26,33-43,45,46,48-50,65,67,68]$} \\
\hline Staphylococcus aureus & 39 & 12 & $0.8-20.0$ & 2 & 2 & $3.3-6.5$ & $\begin{array}{l}{[22,23,26,33,36,38,40-42,46,49} \\
\quad 50,65,67]\end{array}$ \\
\hline Streptococcus viridans & 1 & 1 & 1.7 & 1 & 1 & 3.3 & {$[22,36]$} \\
\hline \multicolumn{8}{|l|}{ Gram-negative bacteria } \\
\hline $\begin{array}{l}\text { Gram-negative enteric } \\
\text { bacillic }^{\mathrm{c}}\end{array}$ & 39 & 10 & $0.6-42.9$ & 3 & 2 & $1.7-7.8$ & {$[22,23,25,34,37,40,41,45,46,48-50]$} \\
\hline Haemophilus influenzae & 45 & 15 & $1.1-29.4$ & 6 & 5 & $3.2-19.2$ & {$[22,23,25,26,33-43,45,46,48-50,65]$} \\
\hline Pseudomonas aeruginosa & 14 & 10 & $0.9-16.8$ & 2 & 2 & $5.9-6.7$ & {$[22,24,26,34,36,38,41-43,45,49,67]$} \\
\hline Pseudomonas species ${ }^{\mathrm{d}}$ & 19 & 1 & $0.2-3.2$ & 1 & 1 & 19.4 & {$[33,41]$} \\
\hline Klebsiella pneumoniae & 5 & 5 & $0.3-5.0$ & 1 & 1 & 3.3 & {$[24,26,36,38,42,43]$} \\
\hline Moraxella catarrhalis & 28 & 5 & $0.3-2.3$ & 0 & 0 & - & {$[26,40-42,46]$} \\
\hline Serratia marcescens & 1 & 1 & 2.3 & 1 & 1 & 3.3 & {$[26,36]$} \\
\hline Escherichia coli & 5 & 3 & $0.6-2.1$ & 1 & 1 & 6.7 & {$[36,38,42,43]$} \\
\hline \multicolumn{8}{|l|}{ Atypical bacteria } \\
\hline Mycoplasma pneumoniae & 39 & 10 & $0.7-61.3$ & 0 & 0 & - & {$[22,23,38-43,45,65]$} \\
\hline Legionella pneumophila & 19 & 12 & $1.7-20.1$ & 5 & 4 & $3.2-15.1$ & $\begin{array}{l}{[22,25,26,34-36,38-40,42,43,45,46,} \\
\quad 48-50]\end{array}$ \\
\hline Legionella species $^{\mathrm{e}}$ & 27 & 3 & $5.4-20.0$ & 0 & 0 & - & {$[23,41,67]$} \\
\hline $\begin{array}{l}\text { Chlamydophila } \\
\text { pneumoniae }\end{array}$ & 29 & 9 & $0.1-9.9$ & 0 & 0 & - & {$[22,23,26,38,39,41-43,45]$} \\
\hline Coxiella burnetii & 9 & 6 & $0.8-3.4$ & 0 & 0 & - & {$[22,26,38,40,43,45]$} \\
\hline Virus & 38 & 10 & $1.4-28.6$ & 1 & 1 & 0.7 & {$[22,23,38,40-42,45,46,48,49,65]$} \\
\hline
\end{tabular}

CAP community-acquired pneumonia

Pathogens only reported in one cohort in one study were excluded

${ }^{a}$ Percentages are based on the number of patients/episodes in which pathogens were identified and data were available

${ }^{\mathrm{b}}$ For studies that only reported data separately for each cohort, all cohorts were included; for studies that reported data for the overall study population, the summary data were used. Studies performed in patients with pneumonia due to a specific pathogen were excluded

${ }^{\mathrm{c}}$ For studies $[22,23,25,34,37,40,41,45,46,48-50]$, Gram-negative enteric bacilli were grouped together and individual pathogens in this group were not reported separately

${ }^{\mathrm{d}}$ For studies [33, 41], Pseudomonas species were not reported separately and, therefore, could include P. aeruginosa

${ }^{\mathrm{e}}$ For studies [23, 41, 67], Legionella species were not reported separately and, therefore, could include L. pneumophila

Erythromycin resistance of $S$. pneumoniae was observed in $12.0-21 \%$ of patients with CAP and in $14.7-17.1 \%$ of isolates. In the two studies reporting on the antibiotic resistance of $H$. influenzae, beta-lactamase production was reported in $9.7 \%$ [43] and $80.0 \%$ [30] of isolates.

\section{Discussion}

This review provides a comprehensive overview of the aetiology of CAP and its antibiotic treatment in patients in Western Europe and builds on knowledge from earlier reviews of the incidence and risk factors for CAP among adults in this region [7], the burden of CAP in Europe [1] and a metaanalysis on the incidence of CAP in Europe by Rozenbaum et al. [12]. In addition, it provides important information to be taken into consideration in future updates to the European guidelines for the management of CAP.

Microbiological methodologies for the isolation of pathogens

The majority of studies were in patients hospitalised for CAP and, as may be expected, blood cultures were used for the isolation of pathogens. This is in line with current guidelines from the European Respiratory Society (ERS) and the European Society for Clinical Microbiology and Infectious 
Table 4 Prevalence of pathogens identified in patients with CAP with HIV or COPD

\begin{tabular}{|c|c|c|c|c|c|c|}
\hline \multirow[t]{4}{*}{ Aetiology } & \multicolumn{3}{|l|}{ HIV } & \multicolumn{3}{|l|}{ COPD } \\
\hline & \multirow{3}{*}{$\begin{array}{l}\text { Patients with pathogen } \\
\text { identified }^{\mathrm{a}} \\
\text { Range (\%) }\end{array}$} & \multirow{3}{*}{$\begin{array}{l}\text { Episodes with pathogen } \\
\text { identified }^{\mathrm{a}} \\
\text { Range (\%) }\end{array}$} & \multirow[t]{3}{*}{ References } & \multirow{2}{*}{\multicolumn{2}{|c|}{$\begin{array}{l}\begin{array}{l}\text { Patients with } \\
\text { pathogen identified }^{\text {a }}\end{array} \\
\text { Range (\%) }\end{array}$}} & \multirow[t]{3}{*}{ References } \\
\hline & & & & & & \\
\hline & & & & COPD & No COPD & \\
\hline \multicolumn{7}{|l|}{ Gram-positive bacteria } \\
\hline Streptococcus pneumoniae & $57.8-81.8$ & $42.9-71.4$ & {$[33-37]$} & $37.5-66.3$ & $26.9-57.0$ & {$[38,40,42]$} \\
\hline Staphylococcus aureus & 6.5 & 3.3 & {$[33,36]$} & 1.1 & $0.8-3.2$ & {$[38,40,42]$} \\
\hline \multicolumn{7}{|l|}{ Gram-negative bacteria } \\
\hline $\begin{array}{l}\text { Gram-negative enteric } \\
\text { bacillib }^{\mathrm{b}}\end{array}$ & 7.8 & $7.1-42.9$ & {$[33,34]$} & 16.7 & 3.1 & {$[40]$} \\
\hline Haemophilus influenzae & $3.2-9.1$ & $6.7-14.3$ & {$[33-37]$} & $1.1-4.2$ & $1.7-3.8$ & {$[38,40,42]$} \\
\hline Pseudomonas aeruginosa & 5.9 & 6.7 & {$[34,36]$} & $2.1-7.4$ & 0.9 & {$[38,42]$} \\
\hline Escherichia coli & - & 6.7 & {$[36]$} & $1.1-2.6$ & $1.1-1.3$ & {$[38,42]$} \\
\hline Klebsiella pneumoniae & - & 3.3 & {$[36]$} & 1.1 & 0.9 & {$[38,42]$} \\
\hline Moraxella catarrhalis & - & - & & 2.1 & 0.4 & {$[40,42]$} \\
\hline Mycoplasma pneumoniae & - & - & & $2.1-4.2$ & $3.4-23.1$ & {$[38,40,42]$} \\
\hline Legionella pneumophila & $9.1-10.8$ & 3.3 & {$[34-36]$} & $2.1-12.5$ & $1.7-3.8$ & {$[38,40,42]$} \\
\hline Chlamydophila pneumoniae & - & - & & $2.1-6.3$ & $4.1-4.5$ & {$[38,40,42]$} \\
\hline Coxiella burnetii & - & - & & 2.1 & $1.5-3.4$ & {$[38,40]$} \\
\hline Virus & - & - & & $4.2-13.7$ & $2.8-12.5$ & {$[38,40,42]$} \\
\hline
\end{tabular}

$C A P$ community-acquired pneumonia; $C O P D$ chronic obstructive pulmonary disease; $H I V$, human immunodeficiency virus

${ }^{a}$ Percentages are based on the number of patients/episodes in which pathogens were identified and data were available

${ }^{b}$ For studies [33, 34, 40], Gram-negative enteric bacilli were grouped together and individual pathogens in this group were not reported separately

Diseases (ESCMID) for the management of lower respiratory tract infections, which recommend that two sets of blood cultures are performed in patients hospitalised for CAP [18].
However, a study conducted between 2007 and 2011 in 14 countries in Europe found that blood cultures were performed in only $50 \%$ of patients hospitalised with CAP [51]. This is

Table 5 Antibiotic treatment in adults with CAP

\begin{tabular}{lllll}
\hline Antibiotic & Cohorts $(n)^{\mathrm{a}}$ & Studies $(n)$ & $\begin{array}{l}\text { Patients treated with } \\
\text { antibiotic }{ }^{\mathrm{b}} \text {, range (\%) }\end{array}$ & References \\
\hline Monotherapy & 31 & 7 & $16.0-94.7$ & {$[22,40,41,43,44,46,47]$} \\
Beta-lactams & 32 & 8 & $5.0-87.7$ & {$[22,37,38,40,41,43,44,47]$} \\
Macrolides & 30 & 6 & $0.3-47.7$ & {$[37,38,40,41,44,47]$} \\
Quinolones & 32 & 8 & $2.0-46.0$ & {$[22,37,38,40,41,43,44,47]$} \\
Other & 26 & 3 & $0.7-8.8$ & {$[40,41,43]$} \\
Combination therapy & 33 & 8 & $5.0-84.0$ & {$[22,37,40,41,43,44,46,47]$} \\
Beta-lactam + macrolide & 10 & 7 & $1.7-70.0$ & {$[22,38,40,43-45,47]$} \\
Beta-lactam + quinolone & 4 & 4 & $6.3-63.0$ & {$[22,43,44,47]$} \\
Macrolide + quinolone & 2 & 2 & $0.9-1.0$ & {$[44,47]$} \\
Other & 5 & 4 & $2.0-38.0$ & {$[38,43,44,47]$} \\
\hline
\end{tabular}

CAP community-acquired pneumonia

${ }^{a}$ For studies that only reported data separately for each cohort, all cohorts were included; for studies that reported data for the overall study population, the summary data were used. Studies performed in patients with pneumonia due to a specific pathogen were excluded

${ }^{\mathrm{b}}$ Percentages are based on patients with available data 
Table 6 Antibiotic treatment in adults with CAP stratified by ICU patients, hospitalised patients and outpatients

\begin{tabular}{|c|c|c|c|c|c|c|c|}
\hline \multirow[t]{2}{*}{ Antibiotic } & \multicolumn{2}{|c|}{ ICU patients } & \multicolumn{2}{|c|}{ Hospitalised patients } & \multicolumn{2}{|l|}{ Outpatients } & \multirow[t]{2}{*}{ References } \\
\hline & $\begin{array}{l}\text { Cohorts } \\
(n)^{\mathrm{a}}\end{array}$ & $\begin{array}{l}\text { Patients treated } \\
\text { with antibiotic }{ }^{\mathrm{b}} \text {, } \\
\text { range }(\%)\end{array}$ & $\begin{array}{l}\text { Cohorts } \\
(n)^{\mathrm{a}}\end{array}$ & $\begin{array}{l}\text { Patients treated } \\
\text { with antibiotic }{ }^{\mathrm{b}} \text {, } \\
\text { range }(\%)\end{array}$ & Cohorts $(n)^{\mathrm{a}}$ & $\begin{array}{l}\text { Patients treated } \\
\text { with antibiotic }{ }^{\mathrm{b}} \text {, } \\
\text { range }(\%)\end{array}$ & \\
\hline Monotherapy & 1 & 16.0 & 12 & $30.3-68.2$ & 9 & $70.1-94.7$ & {$[22,41,43-47]$} \\
\hline Beta-lactams & 1 & 5.0 & 13 & $8.0-87.7$ & 9 & $40.1-48.9$ & {$[22,27,37,38,41,43,45,47]$} \\
\hline Macrolides & - & - & 12 & $0.3-47.7$ & 9 & $14.1-22.1$ & {$[22,27,37,38,41,45,47]$} \\
\hline Quinolones & 1 & 11.0 & 13 & $2.0-46.0$ & 9 & $12.0-39.2$ & {$[22,37,38,41,43-45,47]$} \\
\hline Other & - & - & 9 & $0.7-3.6$ & 8 & $5.1-8.8$ & {$[41,43,45]$} \\
\hline Combination therapy & 1 & 84.0 & 14 & $31.8-69.0$ & 9 & $5.0-29.9$ & {$[22,37,41,43-47]$} \\
\hline Beta-lactam + macrolide & 1 & 21.0 & 7 & $1.7-70.0$ & 1 & 0.9 & {$[22,38,43-47]$} \\
\hline Beta-lactam + quinolone & 1 & 63.0 & 2 & $27.0-28.1$ & 1 & 6.3 & {$[22,43,44,47]$} \\
\hline Macrolide + quinolone & - & - & 1 & 1.0 & 1 & 0.9 & {$[44,47]$} \\
\hline Other & - & - & 4 & $2.0-38.0$ & 1 & 11.4 & {$[38,43,44,47]$} \\
\hline
\end{tabular}

$C A P$ community-acquired pneumonia; $I C U$ intensive care unit

${ }^{a}$ For studies that only reported data separately for each cohort, all cohorts were included; for studies that reported data for the overall study population, the summary data were used. Studies performed in patients with pneumonia due to a specific pathogen were excluded

${ }^{\mathrm{b}}$ Percentages are based on patients with available data

similar to findings from a further retrospective, observational study in Europe conducted between 2010 and 2011 and published after the cut-off date for our search, in which blood cultures were performed in $55 \%$ of patients hospitalised with CAP, suggesting that implementation of the guidelines across Europe is still incomplete [52]. It is also possible that some European hospitals have adopted the approach advocated within the most recent Infectious Diseases Society of America (IDSA)/ American Thoracic Society (ATS) recommendations, which limit blood cultures to patients hospitalised in the ICU [53].

It is important to note that there are limitations in the methodologies used to evaluate the aetiology of CAP; for example, it is difficult to obtain all types of samples in all patients and many patients have received antibiotic treatment prior to sampling. Further limitations include the difficulty in obtaining a reliable sputum sample in the early stages of CAP in non-COPD patients and the technical limitations of diagnostic tests, such as a lack of sensitivity, or the poor ability of patients to form antibodies. Such limitations can lead to inaccurate estimations of the prevalence of pathogens [54]. Furthermore, there are often a substantial number of patients in which the aetiology of CAP cannot be identified. Therefore, the rates of isolated pathogens reported in studies could be under- or overestimated due to false-negative or false-positive results, or the inability to isolate a pathogen [54].

\section{Aetiology of CAP in Europe}

We found that S. pneumoniae was the most common pathogen isolated in patients with CAP in Europe across the studies included in our review. However, there was substantial variation in the incidence of this pathogen $(12.0-85.0 \%$ of patients), which is comparable with findings from Welte et al., which identified S. pneumoniae in $11.9-68.3 \%$ of patients with CAP, and from the meta-analysis by Rozenbaum et al. on the incidence of CAP in Europe, which identified S. pneumoniae in $19.3 \%$ of CAP episodes [1, 12].

Other frequently identified pathogens found to cause CAP across the included studies in our review were $H$. influenzae, Gram-negative enteric bacilli, respiratory viruses and M. pneumoniae. These pathogens were identified at rates similar to those found by Welte et al. [1], with the exception of M. pneumoniae, which was higher in our review $(61.3 \%$ vs. $32.4 \%$ of patients). The high level of M. pneumoniae in our review was influenced by one study in particular, which consistently identified high $M$. pneumoniae rates in the age cohorts studied, particularly the younger cohorts [41]. A possible reason for these high rates of $M$. pneumoniae is the cyclical nature of $M$. pneumoniae outbreaks, which occur every 3-7 years; hence, the prevalence of this organism in a given study varies with the inclusion of such yearly epidemics. Secondly, the study methodology for isolating M. pneumoniae used polymerase chain reaction (PCR) from bronchoalveolar lavage and throat swab samples, which were available for almost all patients, as well as sputum samples, which were available in only approximately $40 \%$ of patients. Therefore, the true denominator for calculating M. pneumoniae rates differed from that for other pathogens, which resulted in an overestimation of the M. pneumoniae rate by two-fold [41]. 
We found that the multidrug-resistant pathogens accounted for $\leq 20.0 \%$ of CAP and that, of these pathogens, $S$. aureus and $P$. aeruginosa were more frequently isolated than $K$. pneumoniae or A. baumannii, which were rarely identified as the cause of CAP. In a European study of pathogens in hospitalised patients with CAP, multidrug-resistant pathogens were the cause of CAP in 3.3-7.6\% of patients in which a pathogen could be identified, with methicillin-resistant S. aureus being the most common multidrug-resistant pathogen [55]. The study also found that patients with CAP caused by multidrugresistant pathogens typically presented with more severe pneumonia on admission to hospital and, correspondingly, multidrug-resistant pathogens were more prevalent among those patients admitted to an ICU than among those admitted to a general ward [55]. Overall, multidrug-resistant pathogens do not appear to be a major cause of CAP in Europe, but the severity of CAP caused by multidrug-resistant pathogens highlights the importance of routine testing for these pathogens. Probabilistic scores, such as the Aliberti and Shorr scores, can be useful for predicting the presence of multidrug-resistant pathogens in hospitalised patients and could help physicians to prescribe appropriate treatments without overprescribing broad-spectrum antibiotics [55].

The frequency of pneumonia of mixed aetiology varied across the four studies in which it was identified, from 0.4 to $19.9 \%$ of patients. One important factor likely to contribute to this variation is the diagnostic methods used to identify pathogens. It is probable that a higher percentage of polymicrobial infections will be identified using newer molecular techniques. These techniques are also likely to contribute to an increase in the percentage of infections in which a causative pathogen can be identified, reducing underdiagnosis and increasing the accuracy of diagnoses, which will potentially lead to improvements in the accuracy of treatment.

Differences in the groupings of pathogens between studies (e.g. Gram-negative enteric bacilli $\pm P$. aeruginosa) may have led to underestimations in the prevalence of some pathogens, such as P. aeruginosa. As for S. pneumoniae, we generally found large ranges in the frequency of pathogens isolated across studies. Differences in the isolation rates of pathogens between studies could be due to many factors, including the severity of CAP, healthcare settings (e.g. patients treated in the community versus in the ICU), populations studied (e.g. age, comorbidities, risk factors) and diagnostic tests used (e.g. traditional methods versus new technology). For example, in a meta-analysis of the prevalence of S. pneumoniae in Europe, S. pneumoniae was more likely to be detected in studies that used PCR assays compared with studies that used other diagnostics tests (OR 2.49 [95\% CI 1.39-4.46]) [12]. To establish the aetiology of CAP in Europe more accurately, improvements are needed in the sensitivity and specificity of diagnostic tests used to isolate pathogens. Furthermore, a more standardised approach to the diagnostic tests used will make comparisons across different studies more valid.
When looking at the aetiology of CAP stratified by age, we found a trend for $S$. pneumoniae, $H$. influenzae and respiratory viruses to be more frequent in elderly patients aged $\geq 65$ years, and $M$. pneumoniae to be more frequent in those aged $<65$ years. Similar age-related trends have been observed previously in a study of the microbial aetiology of CAP in adults in Finland [54], in which S. pneumoniae infections were more frequent in adults aged $\geq 60$ years than in those aged $<60$ years ( $48 \%$ vs. $35 \%, p=0.04$ ) and infections with M. pneumoniae were more frequent in individuals aged $15-$ 44 years compared with older adults $(24 \%$ vs. $3 \%, p<0.001)$. The study in Finland also found viruses to be the cause of CAP in a higher proportion of older adults than younger adults; however, this trend was not significant. No consistent age-related trend was observed for $H$. influenzae [54]. A study of the microbial patterns of CAP in patients aged $\geq 65$ years found that $S$. pneumoniae was the most frequent pathogen in all age groups over 65 years and that age did not influence the microbial cause of CAP [6]. In patients with COPD, we found that the aetiology of CAP was similar to that in patients without this condition. This was also observed in patients with HIV (in those who were non-severely immunocompromised or receiving treatment), which is in line with the results from studies examining the impact of HIV on the clinical outcomes of CAP in the highly active antiretroviral therapy era. Nonseverely immunocompromised patients with HIV have been shown to have similar clinical outcomes in terms of the time to clinical stability, length of hospital stay and mortality rate when compared with individuals without HIV $[56,57]$.

\section{Antibiotic treatment in patients with CAP}

Current ERS/ESCMID guidelines (2011 edition) for the treatment of CAP [18] recommend one of the following for the treatment of CAP in hospitalised patients:

- Aminopenicillin \pm macrolide

- Aminopenicillin beta-lactamase inhibitor \pm macrolide

- Non-antipseudomonal cephalosporin III

- Cefotaxime or ceftriaxone \pm macrolide

- Levofloxacin

- Moxifloxacin

- Penicillin $\mathrm{G} \pm$ macrolide

The ERS/ESCMID guidelines suggest that combination therapy should be restricted to patients with severe presentation of CAP, with combination therapy being the treatment of choice for patients with severe CAP being treated in the ICU [18]. In these patients, non-antipseudomonal cephalosporin III plus a macrolide, or moxifloxacin or levofloxacin \pm nonantipseudomonal cephalosporin III are recommended in those patients without risk factors for $P$. aeruginosa, whereas in patients with risk factors for $P$. aeruginosa, antipseudomonal 
cephalosporin, or acylureidopenicillin beta-lactamase inhibitor or carbapenem, plus ciprofloxacin or plus macrolide plus aminoglycoside is preferred. When a specific pathogen has been identified, antibiotic therapy can be targeted against that pathogen. For example, for CAP caused by Legionella species, respiratory quinolones are recommended [18]. In our study, we found that beta-lactams and macrolides were more frequently prescribed than quinolones. This was not unexpected, as some treatment guidelines reserve quinolones for when initial empirical therapy has failed, or specifically for the treatment of CAP caused by Legionella species (which was identified in up to $20.1 \%$ of patients in this review) [58].

Many European countries have their own national guidelines for the treatment of CAP [54, 58-63], which are derived from the European guidelines and take into account the local epidemiology and aetiology of CAP, as well as the national resistance rate against antibiotics, such as penicillins and macrolides. This means that, although some similarities exist and the European guidelines provide a good framework for guidance, there are variations in the antibiotic management of CAP throughout Europe, depending on the specific requirements of each country.

A limited amount of data regarding antibiotic resistance were reported in the studies included in this review. By contrast, Welte et al. found several studies with data on antibiotic resistance [1], possibly due to the use of different literature search criteria (e.g. differences in the time periods reviewed, databases searched, search terms used and inclusion/exclusion criteria applied). Antibiotic resistance against $S$. pneumoniae is the main clinical concern, due to its dominance in the aetiology of CAP. We found that pneumococcal resistance against penicillin was slightly higher than might be expected (8.4-20.7\% of isolates $[44,46])$ when compared with that reported in Europe by the European Antimicrobial Resistance Surveillance Network (EARS-Net) in 2011 (8.8\% of isolates non-susceptible and $2.3 \%$ resistant) [64]. However, this may be because all of the studies in this review reporting penicillin resistance were carried out in Spain, which has one of the highest levels of penicillin resistance of $S$. pneumoniae in Europe [64]. Pneumococcal resistance against erythromycin was similar to that reported by the EARS-Net for macrolides (14.7-17.1\% of isolates [43-46] vs. $14.1 \%$ of isolates) [64]. The literature review by Welte et al. highlighted a trend for increased antibiotic resistance of CAP-related pathogens in Europe, including S. pneumoniae, which showed an increase in resistance to commonly prescribed antibiotics [1]. Globalisation and developments in healthcare may contribute to the changing pattern of the aetiology and antibiotic resistance of CAP. Understanding these changes is essential to guide best practices in the antibiotic management of CAP and to safeguard against the failure of empiric antibiotic treatment. The implementation of global surveillance systems would provide a means for guidelines to be adapted more rapidly in response to such changes.
Strengths and limitations

This literature review was based on a review of published data from Europe that aimed to capture as many studies as possible from the past 7 years. The main strength of this review is that many of the included publications were case-control studies performed with large numbers of patients drawn from registries or primary care databases, rather than small, single-centre studies, thus giving reassurance that they provide a good representation of CAP in European populations. However, this review also has some limitations. There was a lack of a well-defined diagnostic protocol in many of the studies and the percentage of patients or episodes of CAP in which a specific causative pathogen was not identified was high in some studies (26.7-87.3 \% and 44.2$77.0 \%$, respectively). The majority of the included studies were based on patient populations in Spain (20 of 33 studies) and this could potentially limit the validity of extrapolating the data from this review to other European populations.

\section{Conclusion}

In conclusion, this review has highlighted that Streptococcus pneumoniae is the most common pathogen responsible for community-acquired pneumonia (CAP) in adults in Europe and that beta-lactams are the most frequently prescribed class of antibiotics for the treatment of CAP. Understanding the aetiology of CAP and the changing pattern of antibiotic resistance in Europe, together with an increased awareness of the risk factors for CAP, will help clinicians to identify those patients most at risk of developing CAP and provide guidance on the most appropriate treatment.

Acknowledgements The authors take full responsibility for the content of this article and thank Neostar Communications Limited, Oxford, UK (supported by Pfizer, France), for their assistance in preparing the manuscript, including preparing the first draft in close collaboration with the authors and the collation of author comments.

Conflict of interest AT has received consulting fees/honorarium from AstraZeneca, Bayer, Curetis, GlaxoSmithKline, Pfizer and Polyphor. FB has received financial support from AstraZeneca, Pfizer and Zambon, and research grants from Zambon. WEP has received advisory board fees from Astellas, AstraZeneca and Pfizer, and research grants from AstraZeneca, Bayer, Pfizer and Sanofi-Aventis. GV has no conflicts of interest to report. TW has received advisory board fees from Astellas, Basilea, Bayer, Gilead, Novartis and Pfizer, and his institution has received research grants from Bayer and Novartis.

Open AccessThis article is distributed under the terms of the Creative Commons Attribution License which permits any use, distribution, and reproduction in any medium, provided the original author(s) and the source are credited. 


\section{References}

1. Welte T, Torres A, Nathwani D (2012) Clinical and economic burden of community-acquired pneumonia among adults in Europe. Thorax 67:71-79

2. Baik I, Curhan GC, Rimm EB, Bendich A, Willett WC, Fawzi WW (2000) A prospective study of age and lifestyle factors in relation to community-acquired pneumonia in US men and women. Arch Intern Med 160:3082-3088

3. Koivula I, Sten M, Mäkelä PH (1994) Risk factors for pneumonia in the elderly. Am J Med 96:313-320

4. Mannino DM, Davis KJ, Kiri VA (2009) Chronic obstructive pulmonary disease and hospitalizations for pneumonia in a US cohort. Respir Med 103:224-229

5. Polverino E, Torres Marti A (2011) Community-acquired pneumonia. Minerva Anestesiol 77:196-211

6. Cillóniz C, Polverino E, Ewig S, Aliberti S, Gabarrús A, Menéndez R, Mensa J, Blasi F, Torres A (2013) Impact of age and comorbidity on cause and outcome in community-acquired pneumonia. Chest 144:999-1007

7. Torres A, Peetermans WE, Viegi G, Blasi F (2013) Risk factors for community-acquired pneumonia in adults in Europe: a literature review. Thorax 68:1057-1065

8. Blasi F, Mantero M, Santus P, Tarsia P (2012) Understanding the burden of pneumococcal disease in adults. Clin Microbiol Infect 18:7-14

9. Almirall J, Bolíbar I, Vidal J, Sauca G, Coll P, Niklasson B, Bartolomé M, Balanzó X (2000) Epidemiology of communityacquired pneumonia in adults: a population-based study. Eur Respir $\mathrm{J}$ 15:757-763

10. Ewig S, Birkner N, Strauss R, Schaefer E, Pauletzki J, Bischoff H, Schraeder P, Welte T, Hoeffken G (2009) New perspectives on community-acquired pneumonia in 388,406 patients. Results from a nationwide mandatory performance measurement programme in healthcare quality. Thorax 64:1062-1069

11. Trotter CL, Stuart JM, George R, Miller E (2008) Increasing hospital admissions for pneumonia, England. Emerg Infect Dis 14:727-733

12. Rozenbaum MH, Pechlivanoglou P, van der Werf TS, Lo-Ten-Foe JR, Postma MJ, Hak E (2013) The role of Streptococcus pneumoniae in community-acquired pneumonia among adults in Europe: a metaanalysis. Eur J Clin Microbiol Infect Dis 32:305-316

13. Weber D, Berger A, Edelsberg J, Huang X-Y, Oster G (2011) Distribution of pathogens in patients hospitalised for communityacquired pneumonia: analysis of data from US hospitals 2006-2009. In: Proceedings of the 49th Annual Meeting of the Infectious Diseases Society of America (IDSA), October 20-23, 2011, Boston, MA, USA

14. Cunha BA (2008) Atypical pneumonias: current clinical concepts focusing on Legionnaires' disease. Curr Opin Pulm Med $14: 183-194$

15. Defres S, Marwick C, Nathwani D (2009) MRSA as a cause of lung infection including airway infection, community-acquired pneumonia and hospital-acquired pneumonia. Eur Respir J 34:1470-1476

16. Strålin K, Söderquist B (2006) Staphylococcus aureus in communityacquired pneumonia. Chest 130:623

17. Vardakas KZ, Matthaiou DK, Falagas ME (2009) Incidence, characteristics and outcomes of patients with severe community acquiredMRSA pneumonia. Eur Respir J 34:1148-1158

18. Woodhead M, Blasi F, Ewig S, Garau J, Huchon G, Ieven M, Ortqvist A, Schaberg T, Torres A, van der Heijden G, Read R, Verheij TJ; Joint Taskforce of the European Respiratory Society and European Society for Clinical Microbiology and Infectious Diseases (2011) Guidelines for the management of adult lower respiratory tract infections-full version. Clin Microbiol Infect 17(Suppl 6):E1-E59
19. Lim WS, Macfarlane JT, Boswell TC, Harrison TG, Rose D, Leinonen M, Saikku P (2001) Study of community acquired pneumonia aetiology (SCAPA) in adults admitted to hospital: implications for management guidelines. Thorax 56:296-301

20. Garcia-Vidal C, Fernández-Sabé N, Carratalà J, Díaz V, Verdaguer R, Dorca J, Manresa F, Gudiol F (2008) Early mortality in patients with community-acquired pneumonia: causes and risk factors. Eur Respir J 32:733-739

21. Lujan M, Gallego M, Fontanals D, Mariscal D, Rello J (2004) Prospective observational study of bacteremic pneumococcal pneumonia: effect of discordant therapy on mortality. Crit Care Med 32:625-631

22. Cillóniz C, Ewig S, Ferrer M, Polverino E, Gabarrús A, Puig de la Bellacasa J, Mensa J, Torres A (2011) Community-acquired polymicrobial pneumonia in the intensive care unit: aetiology and prognosis. Crit Care 15:R209

23. Kothe H, Bauer T, Marre R, Suttorp N, Welte T, Dalhoff K; Competence Network for Community-Acquired Pneumonia study group (2008) Outcome of community-acquired pneumonia: influence of age, residence status and antimicrobial treatment. Eur Respir $\mathrm{J}$ 32:139-146

24. Almirall J, Rofes L, Serra-Prat M, Icart R, Palomera E, Arreola V, Clavé P (2013) Oropharyngeal dysphagia is a risk factor for community-acquired pneumonia in the elderly. Eur Respir J 41:923-928

25. Cabre M, Serra-Prat M, Palomera E, Almirall J, Pallares R, Clavé $P$ (2010) Prevalence and prognostic implications of dysphagia in elderly patients with pneumonia. Age Ageing 39:39-45

26. Vila-Corcoles A, Ochoa-Gondar O, Rodriguez-Blanco T, Raga-Luria X, Gomez-Bertomeu F; EPIVAC Study Group (2009) Epidemiology of community-acquired pneumonia in older adults: a populationbased study. Respir Med 103:309-316

27. Chidiac $\mathrm{C}$, Che $\mathrm{D}$, Pires-Cronenberger $\mathrm{S}$, Jarraud $\mathrm{S}$, Campèse $\mathrm{C}$, Bissery A, Weinbreck P, Brun-Buisson C, Sollet JP, Ecochard R, Desenclos JC, Etienne J, Vanhems P; French Legionnaires' Disease Study Group (2012) Factors associated with hospital mortality in community-acquired legionellosis in France. Eur Respir J 39:963-970

28. Sopena N, Force L, Pedro-Botet ML, Barrufet P, Sauca G, GarcíaNúñez M, Tolchinsky G, Capdevila JA, Sabrià M (2007) Sporadic and epidemic community legionellosis: two faces of the same illness. Eur Respir J 29:138-142

29. Sopena N, Pedro-Botet L, Mateu L, Tolschinsky G, Rey-Joly C, Sabrià M (2007) Community-acquired legionella pneumonia in elderly patients: characteristics and outcome. J Am Geriatr Soc 55:114-119

30. Kofteridis D, Samonis G, Mantadakis E, Maraki S, Chrysofakis G, Alegakis D, Papadakis J, Gikas A, Bouros D (2009) Lower respiratory tract infections caused by Haemophilus influenzae: clinical features and predictors of outcome. Med Sci Monit 15:CR135CR139

31. Ruiz LA, Gómez A, Jaca C, Martínez L, Gómez B, Zalacain R (2010) Bacteraemic community-acquired pneumonia due to Gram-negative bacteria: incidence, clinical presentation and factors associated with severity during hospital stay. Infection 38:453-458

32. von Baum H, Welte T, Marre R, Suttorp N, Ewig S; CAPNETZ study group (2010) Community-acquired pneumonia through Enterobacteriaceae and Pseudomonas aeruginosa: Diagnosis, incidence and predictors. Eur Respir J 35:598-605

33. Bénard A, Mercié P, Alioum A, Bonnet F, Lazaro E, Dupon M, Neau D, Dabis F, Chêne G; Groupe d'Epidémiologie Clinique du Sida en Aquitaine (2010) Bacterial pneumonia among HIV-infected patients: decreased risk after tobacco smoking cessation. ANRS CO3 Aquitaine Cohort, 20002007. PLoS One 5:e8896 
34. Curran A, Falcó V, Crespo M, Martinez X, Ribera E, Villar del Saz S, Imaz A, Coma E, Ferrer A, Pahissa A (2008) Bacterial pneumonia in HIV-infected patients: use of the pneumonia severity index and impact of current management on incidence, aetiology and outcome. HIV Med 9:609-615

35. Le Moing V, Rabaud C, Journot V, Duval X, Cuzin L, Cassuto JP, Al Kaied F, Dellamonica P, Chêne G, Raffi F; APROCO Study Group (2006) Incidence and risk factors of bacterial pneumonia requiring hospitalization in HIV-infected patients started on a protease inhibitor-containing regimen. HIV Med 7:261-267

36. Madeddu G, Porqueddu EM, Cambosu F, Saba F, Fois AG, Pirina P, Mura MS (2008) Bacterial community acquired pneumonia in HIVinfected inpatients in the highly active antiretroviral therapy era. Infection 36:231-236

37. Manno D, Puoti M, Signorini L, Lapadula G, Cadeo B, Soavi L, Paraninfo G, Allegri R, Cristini G, Viale P, Carosi G (2009) Risk factors and clinical characteristics associated with hospitalization for community-acquired bacterial pneumonia in HIV-positive patients according to the presence of liver cirrhosis. Infection 37:334-339

38. Molinos L, Clemente MG, Miranda B, Alvarez C, del Busto B, Cocina BR, Alvarez F, Gorostidi J, Orejas C; ASTURPAR Group (2009) Community-acquired pneumonia in patients with and without chronic obstructive pulmonary disease. J Infect 58:417-424

39. Falguera M, Carratalà J, Ruiz-Gonzalez A, Garcia-Vidal C, Gazquez I, Dorca J, Gudiol F, Porcel JM (2009) Risk factors and outcome of community-acquired pneumonia due to Gram-negative bacilli. Respirology 14:105-111

40. Gutiérrez F, Masiá M, Rodríguez JC, Mirete C, Soldán B, Padilla S, Hernández I, De Ory F, Royo G, Hidalgo AM (2005) Epidemiology of community-acquired pneumonia in adult patients at the dawn of the 21st century: a prospective study on the Mediterranean coast of Spain. Clin Microbiol Infect 11:788-800

41. Klapdor B, Ewig S, Pletz MW, Rohde G, Schütte H, Schaberg T, Welte T; CAPNETZ Study Group (2012) Community-acquired pneumonia in younger patients is an entity on its own. Eur Respir $\mathrm{J}$ 39:1156-1161

42. Liapikou A, Polverino E, Ewig S, Cillóniz C, Marcos MA, Mensa J, Bello S, Martin-Loeches I, Menéndez R, Torres A (2012) Severity and outcomes of hospitalised community-acquired pneumonia in COPD patients. Eur Respir J 39:855-861

43. Carratalà J, Mykietiuk A, Fernández-Sabé N, Suárez C, Dorca J, Verdaguer R, Manresa F, Gudiol F (2007) Health care-associated pneumonia requiring hospital admission: epidemiology, antibiotic therapy, and clinical outcomes. Arch Intern Med 167:1393-1399

44. Cillóniz C, Ewig S, Polverino E, Muñoz-Almagro C, Marco F, Gabarrús A, Menéndez R, Mensa J, Torres A (2012) Pulmonary complications of pneumococcal community-acquired pneumonia: incidence, predictors, and outcomes. Clin Microbiol Infect 18:1134-1142

45. de Roux A, Cavalcanti M, Marcos MA, Garcia E, Ewig S, Mensa J, Torres A (2006) Impact of alcohol abuse in the etiology and severity of community-acquired pneumonia. Chest 129:1219-1225

46. Viasus D, Garcia-Vidal C, Castellote J, Adamuz J, Verdaguer R, Dorca J, Manresa F, Gudiol F, Carratalà J (2011) Communityacquired pneumonia in patients with liver cirrhosis: clinical features, outcomes, and usefulness of severity scores. Medicine (Baltimore) 90:110-118

47. Viegi G, Pistelli R, Cazzola M, Falcone F, Cerveri I, Rossi A, Ugo Di Maria G (2006) Epidemiological survey on incidence and treatment of community acquired pneumonia in Italy. Respir Med 100:46-55

48. Garcia-Vidal C, Carratalà J, Fernández-Sabé N, Dorca J, Verdaguer R, Manresa F, Gudiol F (2009) Aetiology of, and risk factors for, recurrent community-acquired pneumonia. Clin Microbiol Infect 15:1033-1038
49. Giannella M, Pinilla B, Capdevila JA, Martínez Alarcón J, Muñoz P, López Álvarez J, Bouza E; Estudio de Neumonía En Medicina Interna study Group from the Sociedad Española de Medicina Interna (2012) Pneumonia treated in the internal medicine department: focus on healthcare-associated pneumonia. Clin Microbiol Infect 18:786-794

50. Viasus D, Garcia-Vidal C, Cruzado JM, Adamuz J, Verdaguer R, Manresa F, Dorca J, Gudiol F, Carratalà J (2011) Epidemiology, clinical features and outcomes of pneumonia in patients with chronic kidney disease. Nephrol Dial Transplant 26:2899-2906

51. Reissig A, Mempel C, Schumacher U, Copetti R, Gross F, Aliberti S (2013) Microbiological diagnosis and antibiotic therapy in patients with community-acquired pneumonia and acute COPD exacerbation in daily clinical practice: comparison to current guidelines. Lung 191:239-246

52. Blasi F, Garau J, Medina J, Avila M, McBride K, Ostermann H (2013) Current management of patients hospitalized with community-acquired pneumonia across Europe: outcomes from REACH. Respir Res 14:44

53. Mandell LA, Wunderink RG, Anzueto A, Bartlett JG, Campbell GD, Dean NC, Dowell SF, File TM Jr, Musher DM, Niederman MS, Torres A, Whitney CG; Infectious Diseases Society of America; American Thoracic Society (2007) Infectious Diseases Society of America/American Thoracic Society consensus guidelines on the management of community-acquired pneumonia in adults. Clin Infect Dis 44(Suppl 2):S27-S72

54. Jokinen C, Heiskanen L, Juvonen H, Kallinen S, Kleemola M, Koskela M, Leinonen M, Rönnberg PR, Saikku P, Stén M, Tarkiainen A, Tukiainen H, Pyörälä K, Mäkelä PH (2001) Microbial etiology of community-acquired pneumonia in the adult population of 4 municipalities in eastern Finland. Clin Infect Dis 32:1141-1154

55. Aliberti S, Cilloniz C, Chalmers JD, Zanaboni AM, Cosentini R, Tarsia P, Pesci A, Blasi F, Torres A (2013) Multidrug-resistant pathogens in hospitalised patients coming from the community with pneumonia: a European perspective. Thorax 68:997-999

56. Christensen D, Feldman C, Rossi P, Marrie T, Blasi F, Luna C, Fernandez P, Porras J, Martinez J, Weiss K, Levy G, Lode H, Gross P, File T, Ramirez J; Community-Acquired Pneumonia Organization Investigators (2005) HIV infection does not influence clinical outcomes in hospitalized patients with bacterial community-acquired pneumonia: results from the CAPO international cohort study. Clin Infect Dis 41:554-556

57. Malinis M, Myers J, Bordon J, Peyrani P, Kapoor R, Nakamatzu R, Lopardo G, Torres A, Feldman C, Allen M, Arnold F, Ramirez J (2010) Clinical outcomes of HIV-infected patients hospitalized with bacterial community-acquired pneumonia. Int J Infect Dis $14: \mathrm{e} 22-\mathrm{e} 27$

58. Lim WS, Baudouin SV, George RC, Hill AT, Jamieson C, Le Jeune I, Macfarlane JT, Read RC, Roberts HJ, Levy ML, Wani M, Woodhead MA; Pneumonia Guidelines Committee of the BTS Standards of Care Committee (2009) BTS guidelines for the management of community acquired pneumonia in adults: update 2009. Thorax 64(Suppl 3):iii1-iii55

59. Menéndez R, Torres A, Aspa J, Capelastegui A, Prat C, Rodríguez de Castro F; Sociedad Española de Neumología y Cirugía Torácica (2010) Community acquired pneumonia. New guidelines of the Spanish Society of Chest Diseases and Thoracic Surgery (SEPAR). Arch Bronconeumol 46:543-558

60. Höffken G, Lorenz J, Kern W, Welte T, Bauer T, Dalhoff K, Dietrich E, Ewig S, Gastmeier P, Grabein B, Halle E, Kolditz M, Marre R, Sitter H; Paul-Ehrlich-Society of Chemotherapy; German Respiratory Diseases Society; German Infectious Diseases Society; Competence Network CAPNETZ for the Management of Lower Respiratory Tract Infections and Community-acquired Pneumonia (2010) Guidelines of the Paul-Ehrlich-Society of Chemotherapy, 
the German Respiratory Diseases Society, the German Infectious Diseases Society and of the Competence Network CAPNETZ for the Management of Lower Respiratory Tract Infections and Community-acquired Pneumonia. Pneumologie 64:149-154

61. Blasi F, Bulfoni A, Concia E, Costantino S, Di Rosa S, Iori I, Mazzei T, Schito GC (2002) Gestione delle infezioni delle basse vie respiratorie in medicina interna. GIMI 1:1-69

62. Blasi F, Bulfoni A, Concia E, Costantino S, Giusti M, Iori I, Mazzei T, Schito GC (2010) Attualità nella gestione delle infezioni delle basse vie respiratorie in medicina interna. Ital J Med 4:1-78

63. Torres A, Barberán J, Falguera M, Menéndez R, Molina J, Olaechea P, Rodríguez A; Grupo de la Guía Multidisciplinar para el Manejo de la Neumonía Adquirida en la Comunidad (2013) Multidisciplinary guidelines for the management of community-acquired pneumonia. Med Clin (Barc) 140:223.e1-223.e19

64. European Centre for Disease Prevention and Control (ECDC) (2012) Antimicrobial resistance surveillance in Europe 2011. Annual Report of the European Antimicrobial Resistance Surveillance Network
(EARS-Net). Available online at: http://www.ecdc.europa.eu/en/ publications/Publications/antimicrobial-resistance-surveillanceeurope-2011.pdf. Accessed 2 September 2013

65. Holm A, Nexoe J, Bistrup LA, Pedersen SS, Obel N, Nielsen LP, Pedersen C (2007) Aetiology and prediction of pneumonia in lower respiratory tract infection in primary care. Br J Gen Pract 57:547-554

66. Migliorati PL, Boccoli E, Bracci LS, Sestini P, Melani AS (2006) A survey on hospitalised community-acquired pneumonia in Italy. Monaldi Arch Chest Dis 65:82-88

67. Pérez-Sola MJ, Torre-Cisneros J, Pérez-Zafrilla B, Carmona L, Descalzo MA, Gómez-Reino JJ; BIOBADASER Study Group (2011) Infections in patients treated with tumor necrosis factor antagonists: incidence, etiology and mortality in the BIOBADASER registry. Med Clin (Barc) 137:533-540

68. Bewick T, Sheppard C, Greenwood S, Slack M, Trotter C, George R, Lim WS (2012) Serotype prevalence in adults hospitalised with pneumococcal non-invasive community-acquired pneumonia. Thorax 67:540-545 